\title{
Determinants of Fluoroscopy Time for Invasive Coronary Angiography and Percutaneous Coronary Intervention: Insights from the $\mathrm{NCDR}^{\circledR}$
}

\author{
Reza Fazel, ${ }^{1 *} \mathrm{MD}, \mathrm{MSc}$, Jeptha Curtis, ${ }^{2} \mathrm{MD}$, MPH, Yongfei Wang, ${ }^{2} \mathrm{MS}$, Andrew \\ J. Einstein, ${ }^{3} \mathrm{MD}$, PhD, Rebecca Smith-Bindman, ${ }^{4} \mathrm{MD}$, Thomas T. Tsai, ${ }^{5,6} \mathrm{MD}, \mathrm{MSc}$, \\ Jersey Chen, ${ }^{2}$ MD, MPH, Nilay D. Shah, ${ }^{7}$ PhD, Harlan M. Krumholz, ${ }^{2,8,9,10}$ MD, SM, and \\ Brahmajee K. Nallamothu, ${ }^{11,12} \mathrm{MD}$, MPH
}

\begin{abstract}
Objectives: Identifying the distributions and determinants of fluoroscopy time for invasive coronary angiography (ICA) and percutaneous coronary intervention (PCI). Background: ICA and $\mathrm{PCl}$ are significant contributors to radiation exposure from medical imaging in the US. Fluoroscopy time is a potentially modifiable determinant of radiation exposure for these procedures, but has not been well characterized in contemporary practice. Methods: We evaluated the distribution of fluoroscopy time in patients undergoing ICA and/or $\mathrm{PCI}$ in the CathPCI Registry ${ }^{\circledR}$, stratifying patients by numerous clinical scenarios. Hierarchical models were used to determine patient, procedure, operator and hospital-level factors associated with fluoroscopy time for these procedures. Results: Our study included a total of 3,295,348 ICA and PCI procedures performed by 9,600 operators from January 2005 through June 2009. There was wide variation in fluoroscopy times for these procedures with median [IQR] fluoroscopy times of 2.6 [1.7-4.5] minutes for ICA, 6.7 [4.2-10.8] minutes for ICA in patients with
\end{abstract}

${ }^{1}$ From the Division of Cardiology, Department of Medicine, Emory University School of Medicine, Atlanta, Georgia

${ }^{2}$ The Section of Cardiovascular Medicine, Department of Medicine, Yale University School of Medicine, New Haven, Connecticut

${ }^{3}$ The Department of Medicine, Cardiology Division, and the Department of Radiology, Columbia University Medical Center and New York Presbyterian Hospital, New York

${ }^{4}$ Departments of Radiology and Biomedical Imaging, Epidemiology and Biostatistics, Obstetrics, Gynecology, and Reproductive Sciences, School of Medicine, University of California, San Francisco, California

${ }^{5}$ Denver Veterans Affairs (VA) Medical Center, Denver, Colorado

${ }^{6}$ The Department of Internal Medicine, University of Colorado, Denver, Colorado

${ }^{7}$ The Division of Health Care Policy and Research, Mayo Clinic, Rochester, Minnesota

${ }^{8}$ The Robert Wood Johnson Clinical Scholars Program, Department of Medicine, Yale University School of Medicine, New Haven, Connecticut

${ }^{9}$ The Section of Health Policy and Administration, School of Public Health, Yale University School of Medicine, New Haven, Connecticut

\begin{abstract}
${ }^{10}$ The Center for Outcomes Research and Evaluation, YaleNew Haven Hospital, New Haven, Connecticut

${ }^{11}$ The Veterans Affairs Ann Arbor Health Services Research Ann Arbor, Michigan

${ }^{12}$ Development Center of Excellence and the University of Michigan, Division of Cardiovascular Medicine, Ann Arbor, Michigan
\end{abstract}

Grant sponsor: American College of Cardiology Foundation's National Cardiovascular Data Registry (NCDR).

Conflict of interest: None of the authors have any financial interests, direct or indirect, that might have affected the reporting of this work.

*Correspondence to: Reza Fazel, Emory University, Emory Clinical Cardiovascular Research Institute, Suite 528A, 1462 Clifton Rd, Atlanta 30322, GA. E-mail: rfazel@emory.edu

Received 7 February 2013; Revision accepted 12 May 2013

DOI: $10.1002 / \mathrm{ccd} .24996$

Published online 22 May 2013 in Wiley Online Library (wileyonlinelibrary.com). 
prior coronary artery bypass grafting (CABG), 10.1 [6.0-17.4] minutes for $\mathrm{PCl}, 10.7$ [7.0-16.9] minutes for PCI with ICA, and 16.0 [10.6-24.0] minutes for PCI and ICA in patients with prior CABG. Prolonged fluoroscopy times (>30 minutes) were rare for ICA, but occurred in $6.7 \%$ of PCls and $14.7 \%$ of PCls in patients with prior CABG. After accounting for patient characteristics and procedure complexity, operator and hospital-level factors explained nearly $20 \%$ of the variation in fluoroscopy time. Conclusions: Fluoroscopy times vary widely during ICA and $\mathrm{PCI}$ with operator and hospital-level factors contributing substantially to these differences. A better understanding of potentially modifiable sources of this variation will elucidate opportunities for enhancing the radiation safety of these procedures. $\odot 2013$ Wiley Periodicals, Inc.

Key words: RDA-radiation physics; CATH-diagnostic cardiac catheterization; PCIpercutaneous coronary intervention

\section{INTRODUCTION}

Over one million invasive coronary angiography (ICA) and 490,000 percutaneous coronary intervention (PCI) procedures are performed annually in the United States [1]. These two procedures alone account for nearly $8 \%$ of all radiation exposure from medical imaging in the general population [2-4]. In contrast to protocol-based imaging procedures such as computed tomography or nuclear medicine scans, the performance of ICA and PCI also has inherent variability in its duration, leading to wide ranges of radiation exposure for patients undergoing the same type of procedure [5-7].

In contrast to noncardiac fluoroscopic procedures, fluoroscopy times for ICA and PCI correlate well with air kerma-area product $\left(R^{2}=0.53\right.$ to 0.61$)[6,8]$, the preferred measure for estimating total radiation exposure during such procedures $[9,10]$. Lack of routine use of collimation by cardiologists during ICA and PCI is probably a key reason for this distinction between cardiac and noncardiac fluoroscopic procedures. As fluoroscopy time accounts for the majority of variation in air kerma-area product $[6,8]$, it serves as a practical surrogate measure of total radiation exposure during ICA and PCI. For these reasons and based on the ALARA principle-which states that every reasonable effort should be made to reduce radiation exposure [11,12]-minimizing fluoroscopy time has long been considered a cornerstone of improving radiation safety in cardiac catheterization labs $[13,14]$. Yet, despite its importance, no national benchmarks for ICA and PCI fluoroscopy time, with or without adjusting for procedure complexity, have been previously developed.

Accordingly, we used data from the CathPCI Registry to describe the distribution of fluoroscopy time for ICA and PCI in the United States. In addition to describing overall patterns of fluoroscopy time in contemporary practice, we also evaluated the specific contribution of operator and hospital-level factorsincluding operator volume - on variation in fluoroscopy time after accounting for patient characteristics and procedure complexity. This last analysis was performed to elucidate potential opportunities for further enhancing the radiation safety of these procedures.

\section{MATERIALS AND METHODS}

\section{Data Sources}

We included ICA and PCI procedures that were performed between January 1, 2005 and June 30, 2009 at facilities participating in the CathPCI Registry. Details of the registry's participants, cohorts, and data collection methods have been described previously $[15,16]$. Briefly, the CathPCI Registry is an initiative of the American College of Cardiology Foundation and the Society for Cardiovascular Angiography and Interventions, and is composed of clinical data related to diagnostic ICAs and/or PCIs performed at over 1,000 hospitals in the United States. Participating hospitals submit data pertaining to characteristics of patients, procedure findings and complications, interventions performed, and in-hospital outcomes for all ICA and PCI procedures performed at their facilities.

\section{Study Population}

All ICA and PCI procedures with known fluoroscopy time and operator were eligible for this study. Fluoroscopy time was defined as total fluoroscopy time recorded, during the procedure, to the nearest $0.1-\mathrm{mi}$ nute [17]. Based on specific procedure components and the presence of prior coronary artery bypass grafting $(\mathrm{CABG})$, procedures were categorized into five mutually exclusive groups: (1) ICA, (2) ICA in patients with prior CABG, (3) PCI, (4) PCI and ICA, and (5) PCI and ICA in patients with prior CABG. Procedures with missing values for ICA indication $(n=101)$, PCI lesion location $(n=341)$, clinical presentation $(n=427)$, or hospital census region $(n=6,495)$ were excluded. As only the overall fluoroscopy time for any given procedure was available, fluoroscopy times for combined ICA and PCI procedures with two different 
operators $(n=17,869)$ were assigned to the operator performing the PCI. Importantly, the distribution of fluoroscopy times for procedures with unknown operator $(n=1,142,130)$ was nearly identical to that for procedures with operator identifier recorded (Appendix) suggesting that exclusion of procedures with unknown operator from our study did not lead to a significant bias in fluoroscopy time.

\section{Patient, Procedure, Operator, and Hospital Data}

Patient records included data elements on demographic characteristics (age, gender, race, and insurance status), cardiovascular risk factors (hypertension, dyslipidemia, family history of premature coronary artery disease, diabetes mellitus, end-stage renal disease), cardiovascular disease history (prior myocardial infarction, congestive heart failure, prior PCI, cerebrovascular disease, peripheral vascular disease), clinical presentation (asymptomatic, atypical chest pain, stable angina, unstable angina, non-ST-segment elevation myocardial infarction (non-STEMI), or STEMI). Procedure-related information for ICA without PCI included indication (rule out of coronary artery disease, valvular heart disease, evaluation of cardiomyopathy, preoperative evaluation for non-cardiac surgery, congenital heart disease, or cardiogenic shock within 24 hours prior to procedure), concomitant procedures (right heart catheterization or intra-aortic balloon pump insertion), arterial access site (femoral, radial or brachial), and presence and location (native coronary arteries versus bypass grafts) of coronary stenosis of $\geq 50 \%$. For PCI, lesion location and characteristics (complexity, previously treated lesion, bifurcation lesion), complications (coronary dissection, perforation, no reflow phenomenon), and use of specific intracoronary devices (atherectomy, thrombectomy, or extraction catheter, laser, or embolic protection device) were also included. Significant coronary dissection was defined as the appearance of contrast materials outside the expected luminal dimensions of the target vessel and extending longitudinally $>5 \mathrm{~mm}$ beyond the length of the lesion [18]. Operators were identified based on their Unique Physician Identification Number (UPIN) and/or National Provider Identifier (NPI). Annual operator volume was calculated by dividing the total number of procedures performed by an operator in the study cohort by the number of quarters in which they performed at least one procedure and multiplying this value by four. Operators who performed at least one PCI in the CathPCI Registry during the study period were categorized as interventional cardiologists. Hospital information included data elements on teaching status, number of beds, ownership (government, university, or community/private), and US Census region.

\section{Statistical Analysis}

Our primary outcome was fluoroscopy time. Fluoroscopy times are presented as medians with interquartile ranges (IQRs) given their skewed distribution. Other continuous variables are summarized as mean with standard deviation, and categorical variables are displayed as frequencies and percentages. Hierarchical multivariable regression was used to examine the association between fluoroscopy time and the above-mentioned patient, procedure, operator, and hospital factors after accounting for the potential effects of clustering of patients within operators and hospitals [19]. A two-level hierarchical model was used, with patient and procedure factors included in level 1, and operator and hospital factors in level 2 . Variables included in the hierarchical models consisted of the data elements listed above as well as the year of admission to adjust for potential secular temporal trends in fluoroscopy time. Given concern about the accuracy of very high and low operator volumes, we performed a sensitivity analysis by repeating the hierarchical models after excluding procedures performed by operators with annual volume of $<50$ or $>2,000$ procedures per year $(n=218,101)$. To assess the potential influence of complicated procedures on our estimates, we also performed a separate analysis by repeating the multivariable analyses after excluding procedures in which major complications occurred within the catheterization laboratory, including coronary dissection, coronary perforation, acute coronary vessel closure, or no reflow phenomenon.

Finally, in order to determine the proportion of the overall variation in fluoroscopy time that was related to operator- and hospital-level factors (i.e., level-2 factors in the hierarchical models) we used the intraclass correlation coefficients. In addition to the above analyses, we used fractional polynomial regression to further assess the relationship between fluoroscopy time and operator volume. This approach has the benefit of introducing the possibility of non-linear associations between these two variables without imposing constraints using artificially constructed categories. This relationship was evaluated separately for diagnostic ICA (without PCI) and PCI (with or without ICA). Because of concern about the accuracy of very high or low annual volume estimates, operators with annual volume of the $<50$ or $>2,000$ procedures were excluded from this analysis to minimize the impact of these outliers. The above listed patient, procedure,

Catheterization and Cardiovascular Interventions DOI 10.1002/ccd Published on behalf of The Society for Cardiovascular Angiography and Interventions (SCAI). 


\begin{tabular}{|c|c|c|c|c|}
\hline & \multicolumn{2}{|c|}{ ICA $(n=1,517,930)$} & \multicolumn{2}{|c|}{$\begin{array}{l}\text { ICA (prior CABG) } \\
\quad(\mathrm{n}=255,431)\end{array}$} \\
\hline & $\mathrm{n}$ & $\%$ & $\mathrm{n}$ & $\%$ \\
\hline Female & 703,640 & 46.4 & 74,705 & 29.2 \\
\hline \multicolumn{5}{|l|}{ Age } \\
\hline Under 35 & 23,478 & 1.5 & 334 & 0.1 \\
\hline 35 to $<55$ & 426,473 & 28.1 & 28,838 & 11.3 \\
\hline 55 to $<75$ & 779,988 & 51.4 & 146,315 & 57.3 \\
\hline 75 or over & 287,991 & 19.0 & 79,944 & 31.3 \\
\hline Body mass index $(\mathrm{kg} / \mathrm{m} 2)$, mean $(\mathrm{sd})$ & 30.5 & 7.3 & 29.7 & 6.1 \\
\hline \multicolumn{5}{|l|}{ Race } \\
\hline White & $1,220,849$ & 80.4 & 221,897 & 86.9 \\
\hline Black & 141,896 & 9.3 & 11,920 & 4.7 \\
\hline Other & 155,185 & 10.2 & 21,614 & 8.5 \\
\hline \multicolumn{5}{|l|}{ Comorbidities } \\
\hline Hypertension & $1,053,205$ & 69.4 & 205,347 & 80.4 \\
\hline Dyslipidemia & 922,456 & 60.8 & 206,783 & 81.0 \\
\hline Prior myocardial infarction & 219,660 & 14.5 & 105,701 & 41.4 \\
\hline Congestive heart failure & 156,579 & 10.3 & 53,142 & 20.8 \\
\hline Family history of premature CAD & 395,474 & 26.1 & 69,009 & 27.0 \\
\hline Prior PCI & 303,068 & 20.0 & 106,051 & 41.5 \\
\hline End-stage renal disease & 282,74 & 1.9 & 6,244 & 2.4 \\
\hline Cerebrovascular disease & 138,174 & 9.1 & 43,064 & 16.9 \\
\hline Peripheral vascular disease & 133,329 & 8.8 & 50,160 & 19.6 \\
\hline Chronic lung disease & 263,013 & 17.3 & 49,792 & 19.5 \\
\hline Diabetes mellitus & 426,841 & 28.1 & 104,044 & 40.7 \\
\hline Commercial insurance & 470,851 & 31.0 & 50,706 & 19.9 \\
\hline \multicolumn{5}{|l|}{ Clinical presentation } \\
\hline No symptoms & 381,455 & 25.1 & 57,215 & 22.4 \\
\hline Atypical chest pain & 353,262 & 23.3 & 35,455 & 13.9 \\
\hline Stable angina & 237,111 & 15.6 & 46,368 & 18.2 \\
\hline Unstable angina & 401,359 & 26.4 & 90,295 & 35.4 \\
\hline Non-ST-segment elevation MI & 115,621 & 7.6 & 23,021 & 9.0 \\
\hline ST-segment elevation MI & 29,122 & 1.9 & 3,077 & 1.2 \\
\hline \multicolumn{5}{|l|}{ Indication } \\
\hline Rule out CAD & $1,430,005$ & 94.2 & 238,772 & 93.5 \\
\hline Valvular heart disease & 138,253 & 9.1 & 25,750 & 10.1 \\
\hline Evaluation of cardiomyopathy & 407,452 & 26.8 & 110,681 & 43.3 \\
\hline Pre-operative evaluation for non-cardiac surgery & 53,128 & 3.5 & 8,168 & 3.2 \\
\hline Congenital heart disease & 4,805 & 0.3 & 320 & 0.1 \\
\hline Cardiogenic shock within 24 hours & 13,660 & 0.9 & 2,325 & 0.9 \\
\hline \multicolumn{5}{|l|}{ Arterial access site } \\
\hline Femoral & $1,488,066$ & 98.0 & 252,328 & 98.8 \\
\hline Brachial & 7,538 & 0.5 & 1,824 & 0.7 \\
\hline Radial & 22,326 & 1.5 & 1,279 & 0.5 \\
\hline Intraaortic balloon pump inserted & 21,864 & 1.4 & 1,992 & 0.8 \\
\hline Concomitant right heart catheterization & 205,457 & 13.5 & 29,713 & 11.6 \\
\hline \multicolumn{5}{|l|}{ Coronary artery stenosis present } \\
\hline Native coronary vessels & 519,639 & 34.2 & 244,526 & 95.7 \\
\hline Bypass grafts & $\mathrm{n} / \mathrm{a}$ & $\mathrm{n} / \mathrm{a}$ & 99,733 & 39.0 \\
\hline Operator volume, mean (sd) & 325 & 385 & 338 & 360 \\
\hline Operator subspecialty (interventional) & $1,320,128$ & 87.0 & 226,400 & 88.6 \\
\hline Teaching hospital & 767,367 & 50.6 & 130,581 & 51.1 \\
\hline Hospital size $>250$ beds & $1,208,384$ & 79.6 & 205,710 & 80.5 \\
\hline \multicolumn{5}{|l|}{ Census region } \\
\hline Northeast & 252,195 & 16.6 & 40,464 & 15.8 \\
\hline South & 638,205 & 42.0 & 109,765 & 43.0 \\
\hline Midwest & 430,514 & 28.4 & 74,380 & 29.1 \\
\hline West & 197,016 & 13.0 & 30,822 & 12.1 \\
\hline \multicolumn{5}{|l|}{ Ownership } \\
\hline Government & 19,689 & 1.3 & 3,615 & 1.4 \\
\hline Private/community & $1,340,446$ & 88.3 & 225,614 & 88.3 \\
\hline University & 157,795 & 10.4 & 26,202 & 10.3 \\
\hline \multicolumn{5}{|l|}{ Year of procedure } \\
\hline 2005 & 203,492 & 13.4 & 35,297 & 13.8 \\
\hline 2006 & 281,245 & 18.5 & 47,853 & 18.7 \\
\hline 2007 & 360,301 & 23.7 & 60,843 & 23.8 \\
\hline 2008 & 432,796 & 28.5 & 72,228 & 28.3 \\
\hline 2009 & 240,096 & 15.8 & 39,210 & 15.4 \\
\hline
\end{tabular}

CABG, coronary artery bypass graft; CAD, coronary artery disease; MI, myocardial infarction. 
TABLE II. Characteristics of Patients Undergoing Percutaneous Coronary Intervention (PCI)

\begin{tabular}{|c|c|c|c|c|c|c|}
\hline & \multicolumn{2}{|c|}{$\begin{array}{c}\text { PCI } \\
(\mathrm{n}=318,779)\end{array}$} & \multicolumn{2}{|c|}{$\begin{array}{l}\text { PCI and ICA } \\
(\mathrm{n}=988,719)\end{array}$} & \multicolumn{2}{|c|}{$\begin{array}{l}\text { PCI and ICA } \\
\text { (prior CABG) } \\
(\mathrm{n}=214,489)\end{array}$} \\
\hline & $\mathrm{n}$ & $\%$ & $\mathrm{n}$ & $\%$ & $\mathrm{n}$ & $\%$ \\
\hline Female & 108,630 & 34.1 & 342,001 & 34.6 & 56,716 & 26.4 \\
\hline \multicolumn{7}{|l|}{ Age } \\
\hline Under 35 & 1,124 & 0.4 & 6,255 & 0.6 & 206 & 0.1 \\
\hline 35 to $<55$ & 58,568 & 18.4 & 251,721 & 25.5 & 24,767 & 11.5 \\
\hline 55 to $<75$ & 176,941 & 55.5 & 526,823 & 53.3 & 125,641 & 58.6 \\
\hline 75 or over & 82,146 & 25.8 & 203,920 & 20.6 & 63,875 & 29.8 \\
\hline Body mass index $\left(\mathrm{kg} / \mathrm{m}^{2}\right)$, mean $(\mathrm{sd})$ & 29.9 & 6.3 & 29.8 & 6.4 & 29.6 & 5.9 \\
\hline \multicolumn{7}{|l|}{ Race } \\
\hline White & 272,215 & 85.4 & 825,790 & 83.5 & 187,029 & 87.2 \\
\hline Black & 20,777 & 6.5 & 65,476 & 6.6 & 9,783 & 4.6 \\
\hline Other & 25,787 & 8.1 & 97,453 & 9.9 & 17,677 & 8.2 \\
\hline \multicolumn{7}{|l|}{ Comorbidities } \\
\hline Hypertension & 261,642 & 82.1 & 739,809 & 74.8 & 187,145 & 87.3 \\
\hline Dyslipidemia & 253,627 & 79.6 & 715,885 & 72.4 & 189,167 & 88.2 \\
\hline Prior myocardial infarction & 95,437 & 29.9 & 217,493 & 22.0 & 101,298 & 47.2 \\
\hline Congestive heart failure & 41,504 & 13.0 & 78,320 & 7.9 & 41,220 & 19.2 \\
\hline Family history of premature CAD & 77,133 & 24.2 & 252,542 & 25.5 & 57,256 & 26.7 \\
\hline Prior PCI & 125,073 & 39.2 & 322,018 & 32.6 & 114,869 & 53.6 \\
\hline End-stage renal disease & 6,607 & 2.1 & 15,583 & 1.6 & 5,187 & 2.4 \\
\hline Cerebrovascular disease & 42,372 & 13.3 & 92,517 & 9.4 & 38,558 & 18.0 \\
\hline Peripheral vascular disease & 45,411 & 14.2 & 91,053 & 9.2 & 44,732 & 20.9 \\
\hline Chronic lung disease & 57,719 & 18.1 & 151,799 & 15.4 & 39,107 & 18.2 \\
\hline Diabetes mellitus & 116,346 & 36.5 & 299,150 & 30.3 & 94,142 & 43.9 \\
\hline Commercial insurance & 86,197 & 27.0 & 314,768 & 31.8 & 47,376 & 22.1 \\
\hline \multicolumn{7}{|l|}{ Clinical presentation } \\
\hline No symptoms & 59,849 & 18.8 & 111,398 & 11.3 & 24,933 & 11.6 \\
\hline Atypical chest pain & 21,905 & 6.9 & 74,379 & 7.5 & 14,512 & 6.8 \\
\hline Stable angina & 65,188 & 20.4 & 134,238 & 13.6 & 35,637 & 16.6 \\
\hline Unstable angina & 112,758 & 35.4 & 305,277 & 30.9 & 93,901 & 43.8 \\
\hline Non-ST-segment elevation MI & 39,775 & 12.5 & 170,434 & 17.2 & 33,949 & 15.8 \\
\hline ST-segment elevation MI & 19,304 & 6.1 & 192,993 & 19.5 & 11,557 & 5.4 \\
\hline Cardiogenic shock within 24 hours & 4,022 & 1.3 & 26,625 & 2.7 & 3,333 & 1.6 \\
\hline \multicolumn{7}{|l|}{ Arterial access site } \\
\hline Femoral & 311,907 & 97.8 & 968,916 & 98.0 & 212,138 & 98.9 \\
\hline Brachial & 1,486 & 0.5 & 3,273 & 0.3 & 1,040 & 0.5 \\
\hline Radial & 5,386 & 1.7 & 16,530 & 1.7 & 1,311 & 0.6 \\
\hline Intraaortic balloon pump inserted & 5,486 & 1.7 & 30,758 & 3.1 & 3,683 & 1.7 \\
\hline $\begin{array}{l}\text { Number of lesions intervened } \\
\text { upon: mean (SD) }\end{array}$ & 1.5 & 0.8 & 1.4 & 0.7 & 1.4 & 0.7 \\
\hline $\begin{array}{l}\text { Concomitant right heart } \\
\text { catheterization }\end{array}$ & 1,958 & 0.6 & 44,379 & 4.5 & 11,107 & 5.2 \\
\hline \multicolumn{7}{|l|}{ PCI lesion characteristics } \\
\hline Previously treated lesion & 29,267 & 9.2 & 95,433 & 9.7 & 35,050 & 16.3 \\
\hline Complex lesion (class C) & 135,593 & 42.5 & 409,495 & 41.4 & 100,115 & 46.7 \\
\hline Bifurcation lesion & 47,381 & 14.9 & 123,243 & 12.5 & 21,434 & 10.0 \\
\hline \multicolumn{7}{|l|}{ PCI lesion location } \\
\hline Native coronary vessel & 293,707 & 92.1 & 988,719 & 100.0 & 132,587 & 61.8 \\
\hline Bypass graft- artery & 18,699 & 5.9 & 0 & 0.0 & 65,292 & 30.4 \\
\hline Bypass graft-vein & 1,532 & 0.5 & 0 & 0.0 & 4,433 & 2.1 \\
\hline $\begin{array}{l}\text { Multiple locations (any } \\
\text { combination of above locations) }\end{array}$ & 4,841 & 1.5 & 0 & 0.0 & 12,177 & 5.7 \\
\hline \multicolumn{7}{|l|}{ Use of intracoronary devices } \\
\hline $\begin{array}{l}\text { Atherectomy, thrombectomy } \\
\text { catheter, or laser }\end{array}$ & 14,097 & 4.4 & 61,042 & 6.2 & 11,218 & 5.2 \\
\hline Embolic protection device & 6,796 & 2.1 & 1,275 & 0.1 & 15,855 & 7.4 \\
\hline \multicolumn{7}{|l|}{ Procedural complications } \\
\hline Significant dissection & 10,510 & 3.3 & 29,278 & 3.0 & 5,127 & 2.4 \\
\hline
\end{tabular}


TABLE II. Continued

\begin{tabular}{|c|c|c|c|c|c|c|}
\hline & \multicolumn{2}{|c|}{$\begin{array}{c}\text { PCI } \\
(\mathrm{n}=318,779)\end{array}$} & \multicolumn{2}{|c|}{$\begin{array}{l}\mathrm{PCI} \text { and ICA } \\
(\mathrm{n}=988,719)\end{array}$} & \multicolumn{2}{|c|}{$\begin{array}{l}\text { PCI and ICA } \\
(\text { prior CABG) } \\
(n=214,489)\end{array}$} \\
\hline & $\mathrm{n}$ & $\%$ & $\mathrm{n}$ & $\%$ & $\mathrm{n}$ & $\%$ \\
\hline Coronary perforation & 1,276 & 0.4 & 3,820 & 0.4 & 995 & 0.5 \\
\hline No reflow phenomenon & 3,229 & 1.0 & 13,575 & 1.4 & 3,881 & 1.8 \\
\hline Operator volume & 325 & 363 & 311 & 391 & 333 & 402 \\
\hline Teaching hospital & 160,423 & 50.3 & 515,930 & 52.2 & 112,766 & 52.6 \\
\hline Hospital size $>250$ beds & 266,768 & 83.7 & 816,600 & 82.6 & 178,677 & 83.3 \\
\hline \multicolumn{7}{|l|}{ Census region } \\
\hline Northeast & 41,626 & 13.1 & 155,807 & 15.8 & 30,218 & 14.1 \\
\hline South & 154,464 & 48.5 & 382,764 & 38.7 & 89,494 & 41.7 \\
\hline Midwest & 84,664 & 26.6 & 291,127 & 29.4 & 63,543 & 29.6 \\
\hline West & 38,025 & 11.9 & 159,021 & 16.1 & 31,234 & 14.6 \\
\hline \multicolumn{7}{|l|}{ Ownership } \\
\hline Government & 6,097 & 1.9 & 12,035 & 1.2 & 2,522 & 1.2 \\
\hline Private/community & 278,905 & 87.5 & 871,974 & 88.2 & 187,831 & 87.6 \\
\hline University & 33,777 & 10.6 & 104,710 & 10.6 & 24,136 & 11.3 \\
\hline \multicolumn{7}{|l|}{ Year of procedure } \\
\hline 2005 & 49,392 & 15.5 & 129,498 & 13.1 & 27,915 & 13.0 \\
\hline 2006 & 67,185 & 21.1 & 183,340 & 18.5 & 39,809 & 18.6 \\
\hline 2007 & 74,771 & 23.5 & 234,064 & 23.7 & 50,486 & 23.5 \\
\hline 2008 & 83,833 & 26.3 & 287,065 & 29.0 & 62,312 & 29.1 \\
\hline 2009 & 43,598 & 13.7 & 154,752 & 15.7 & 33,967 & 15.8 \\
\hline
\end{tabular}

operator, and hospital characteristics were included in these models.

Two-tailed $P<0.05$ was considered statistically significant for all tests. All analyses were performed using SAS version 9.2 (SAS Institute, Cary, NC) and Stata version 11 (StataCorp LP, College Station, TX).

\section{RESULTS}

We examined 1,773,361 diagnostic ICAs (without PCI) and 1,521,987 PCIs (with or without ICA) performed in 2,768,434 patients by 9,600 operators at 942 hospitals during the study period. The mean age of patients was $63.5( \pm 12.5)$ years, 1,285,692 (39.0\%) were female, and $535,912(16.3 \%)$ had had prior CABG. Tables I and II display baseline characteristics of the study population stratified by procedure category.

\section{Distribution of Fluoroscopy Times}

Median fluoroscopy times for each procedure category are listed in Table III. There was wide variation in fluoroscopy times for all procedure categories (Fig. 1). The presence of coronary artery bypass grafts was associated with increases of 4.1 and 5.3 minutes in median fluoroscopy times for ICA and ICA with PCI, respectively. ICAs performed for evaluation of patients with valvular heart disease and congenital heart disease were associated with longer fluoroscopy times as com- pared to other indications such as ruling out coronary artery disease (Fig. 2-top panel). These differences in fluoroscopy times by ICA indication were less prominent in patients with prior CABG (Fig. 2-bottom panel).

Fluoroscopy times of greater than 30 minutes were uncommon for ICA but occurred in a sizeable minority of patients undergoing PCI, ranging in this latter group from $6.7 \%$ in patients without prior $\mathrm{CABG}$ to nearly $15 \%$ of those with prior CABG (Table III). Approximately $1.3 \%$ of PCI patients had fluoroscopy times of more than 60 minutes, a threshold beyond which the risk of radiation-related skin injury increases significantly.

\section{Multivariable Analyses}

Incremental fluoroscopy times associated with patient, operator, and hospital factors after multivariable adjustment are listed in Tables IV and V, separately for ICA and PCI. For ICA, factors associated with the largest increments in fluoroscopy time were brachial arterial access (up to 6.0 minutes of added fluoroscopy time), radial arterial access (up to 3.6 minutes), congenital heart disease (3.2 minutes), concomitant right heart catheterization (2.7 minutes), a university hospital setting (up to 2.6 minutes), and presence of coronary stenosis of $\geq 50 \%$ in patients with prior CABG (up to 1.7 minutes) (Table IV). Other factors associated with longer fluoroscopy times during 

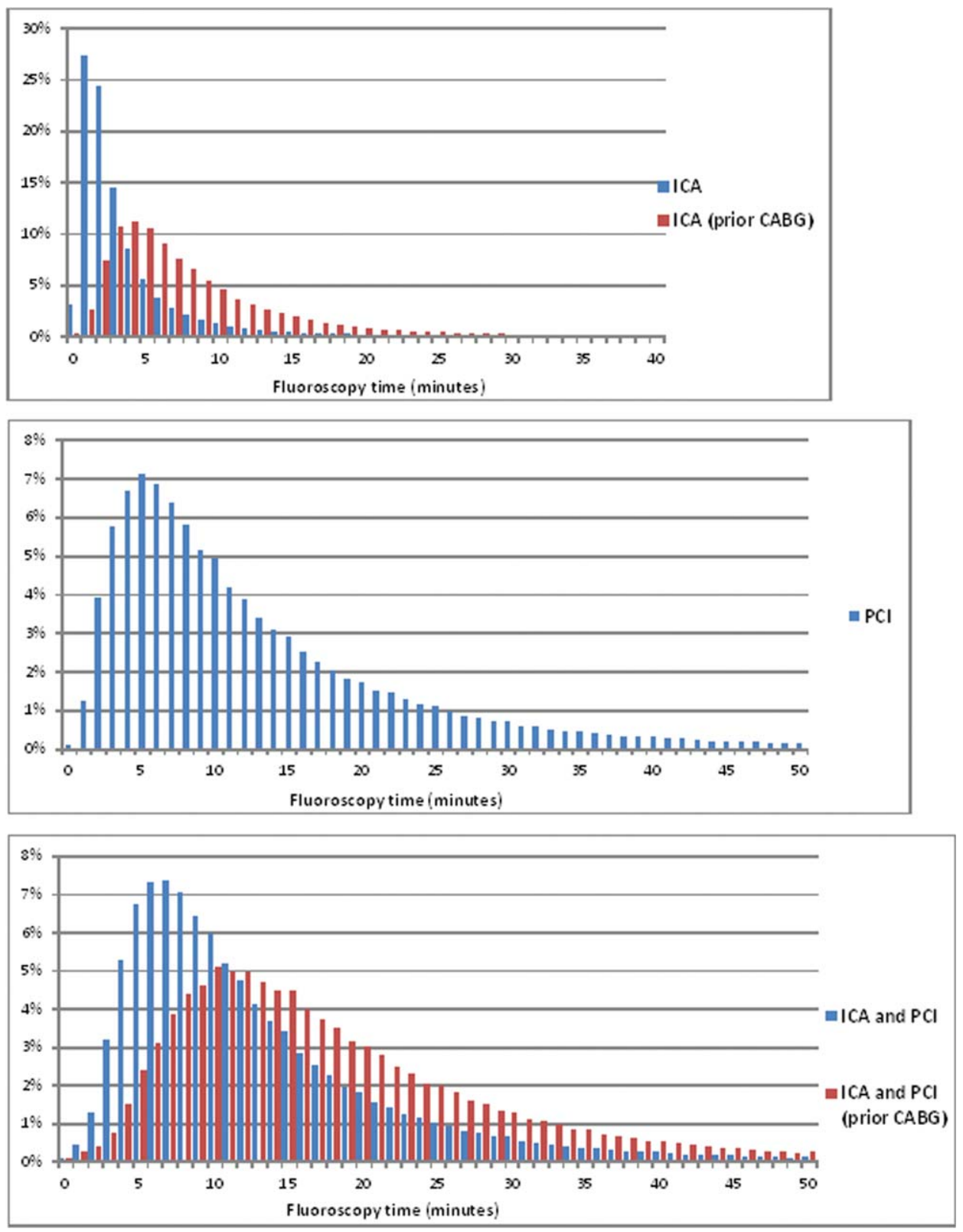

Fig. 1. Distribution of fluoroscopy times for invasive coronary angiography (ICA) and percutaneous coronary intervention (PCI) procedures. CABG indicates coronary artery bypass graft.

ICA included age $\geq 75$ years, peripheral vascular disease, valvular heart disease, and lower operator volume (Table IV).

For PCI, the largest increments in fluoroscopy time were associated with significant coronary dissection or perforation (up to a 7.7 minute increase in fluoroscopy time), use of atherectomy, thrombectomy or extraction catheter or laser (up to 7.1 minutes), brachial artery access (up to 7.2 minutes), number of lesions intervened upon, university hospital setting (up to 4.9 minutes), intra-aortic balloon pump insertion (up to 3.7 minutes), and radial artery access (up to 3.3 minutes) (Table V). In addition, age $\geq 75$ years, endstage renal disease, peripheral vascular disease, concomitant right heart catheterization, complex (class C) or bifurcation lesions, no reflow phenomenon, lower operator volume, and Northeast and West census regions were associated with substantial increases in fluoroscopy time (Table V). Intervention on every additional coronary lesion was associated with an average increase of nearly 4 minutes in fluoroscopy time. Right heart catheterization concomitant with any PCI procedure was, on average, 
associated with 2.1 minutes of additional fluoroscopy time.

Female gender was associated with modestly shorter fluoroscopy times for both ICA and PCI, ranging from 0.3 to 1.3 fewer minutes of fluoroscopy time. Presentation with STEMI was also associated with shorter fluoroscopy times (up to 1.9 minutes) as compared with other clinical presentations. After accounting for patient, procedure, operator, and hospital factors, there was a modest but statistically significant temporal trend for decreasing fluoroscopy times for PCI during the study period (decline of 1.0-1.5 minutes over the study period). There were no significant changes in our

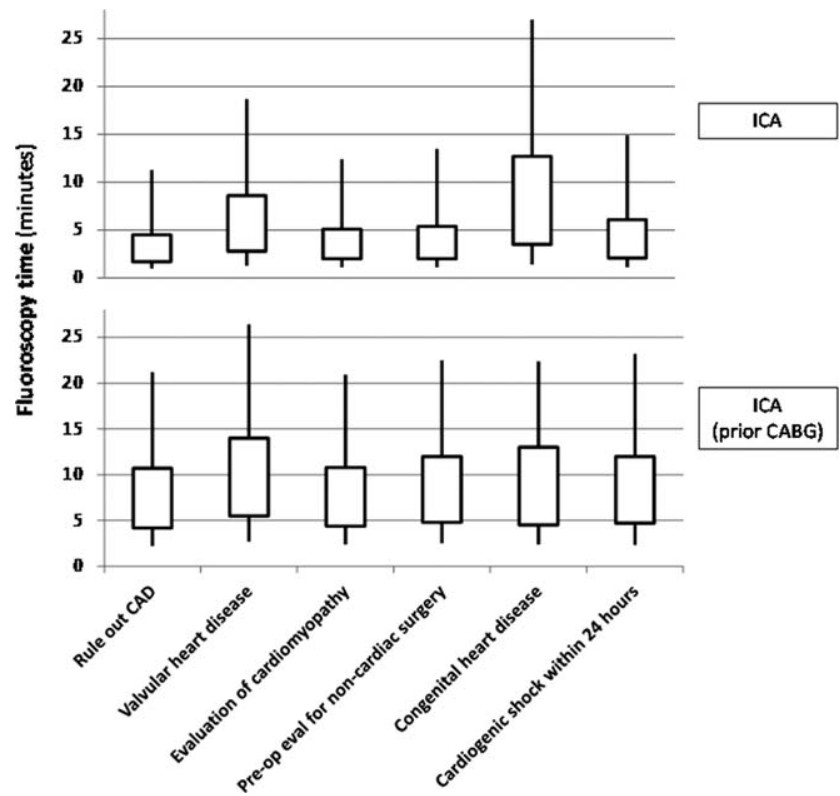

Fig. 2. Distribution of fluoroscopy times for invasive coronary angiography (ICA) stratified by clinical indication in patients without prior CABG (top panel) and with prior CABG (bottom panel). The boxplots denote the interquartile range and the lower and upper whiskers display the 5th and 95th percentiles, respectively. CABG indicates coronary artery bypass graft; CAD, coronary artery disease. results after excluding procedures performed by operators with annual procedure volume of $<50$ or $>2,000$. Similarly, exclusion of procedures in which coronary dissection, coronary perforation, acute coronary vessel closure, or no reflow phenomenon occurred did not significantly alter our findings.

Overall, after accounting for differences in patient characteristics and procedure complexity, operator and hospital-level factors explained $17.0 \%$ and $19.0 \%$ of the variation in fluoroscopy time for ICA and PCI, respectively. Mean operator volume was $118( \pm 148)$ procedures per year with $87.2 \%$ of ICAs performed by an interventional cardiologist. After multivariable adjustment, interventional cardiologists had lower ICA fluoroscopy times as compared to noninterventionalists, particularly in patients with prior CABG. Operators' average fluoroscopy time for each of the five procedure categories varied widely, indicating substantial operator-level variation in fluoroscopy times (Fig. 3).

Operator volume was inversely associated with fluoroscopy time. The magnitude of this association varied by procedure category, ranging from a reduction of 0.50 minutes in fluoroscopy time per 250 cases performed per year for ICA in patients without prior CABG to 1.49 minutes per 250 cases performed per year for ICA with PCI in patients with prior CABG. Fractional polynomials regression analysis confirmed a significant operator volume-fluoroscopy time relationship and also indicated that this relationship was stronger for PCI as compared to ICA (Fig. 4).

\section{DISCUSSION}

In this large, contemporary national registry of patients undergoing ICA and PCI in the United States, we found wide variation in fluoroscopy times for these procedures, including substantial operator and hospitallevel variation. However, we found a large proportion (approximately 80\%) of this variation was "fixed" in

TABLE III. Distribution of Fluoroscopy Time for Invasive Coronary Angiography (ICA) and Percurtaneous Coronary Intervention (PCI)

Table 1. Distribution of fluoroscopy time for ICA and PCI procedures

\begin{tabular}{|c|c|c|c|c|c|}
\hline & ICA & ICA (prior CABG) & PCI & PCI and ICA & $\begin{array}{l}\text { PCI and ICA } \\
\text { (prior CABG) }\end{array}$ \\
\hline Fluoroscopy time (min.), median (IQR) & $2.6(1.7-4.5)$ & $6.7(4.2-10.8)$ & $10.1(6.0-17.4)$ & $10.7(7.0-16.9)$ & $16.0(10.6-24.0)$ \\
\hline 10th percentile, 90 th percentile & $1.2-8.1$ & $2.9-16.5$ & $3.7-28.1$ & $4.9-25.9$ & $7.3-34.6$ \\
\hline 5 th percentile, 95 th percentile & $1.0-11.5$ & $2.2-21.2$ & $2.9-37.0$ & $3.9-33.3$ & $5.8-43.0$ \\
\hline 1st percentile, 99 th percentile & $0.6-23.2$ & $1.3-34.1$ & $1.7-60.3$ & $2.4-53.6$ & $3.3-63.7$ \\
\hline $\begin{array}{l}\text { Mean physician-level fluoroscopy } \\
\text { time (min.), median (IQR) }\end{array}$ & $4.1(3.1-5.4)$ & $9.0(6.9-11.9)$ & $13.6(10.3-18.1)$ & $13.3(10.6-16.7)$ & $18.8(15.0-23.6)$ \\
\hline Fluoroscopy time $>30$ min., no. (\%) & $8,044(0.5 \%)$ & $4,031(1.6 \%)$ & $27,146(8.5 \%)$ & $66,006(6.7 \%)$ & $31,462(14.7 \%)$ \\
\hline Fluoroscopy time $>60 \mathrm{~min}$. , no. $(\%)$ & $1,556(0.1 \%)$ & $351(0.1 \%)$ & $3,226(1.0 \%)$ & $6,205(0.6 \%)$ & $2,810(1.3 \%)$ \\
\hline
\end{tabular}

CABG, coronary artery bypass graft; IQR, interquartile range.

Catheterization and Cardiovascular Interventions DOI 10.1002/ccd.

Published on behalf of The Society for Cardiovascular Angiography and Interventions (SCAI). 
TABLE IV. Incremental ICA Fluoroscopy Time (in Minutes, with 95\% Cl) Associated with Listed Variables After Multivariable Adjustment

\begin{tabular}{|c|c|c|c|c|}
\hline \multirow{2}{*}{$\frac{\text { Variable }}{\text { Female gender }}$} & \multicolumn{2}{|c|}{ ICA } & \multicolumn{2}{|c|}{ ICA (prior CABG) } \\
\hline & -0.31 & $(-0.33$ to -0.29$)$ & -0.83 & $(-0.89$ to -0.77$)$ \\
\hline \multicolumn{5}{|l|}{ Age } \\
\hline Under 35 & -0.51 & $(-0.59$ to -0.44$)$ & -2.06 & $(-2.80$ to -1.32$)$ \\
\hline 35 to $<55$ & -0.83 & $(-0.86$ to -0.80$)$ & -1.82 & $(-1.92$ to -1.71$)$ \\
\hline 55 to $<75$ & -0.60 & $(-0.62$ to 0.57$)$ & -0.98 & $(-1.04$ to -0.91$)$ \\
\hline 75 or over & Ref & Ref & Ref & Ref \\
\hline Body mass index (per kg/m2) & 0.015 & (0.014 to 0.016$)$ & 0.03 & (0.03 to 0.04$)$ \\
\hline \multicolumn{5}{|l|}{ Race } \\
\hline White & Ref & Ref & Ref & Ref \\
\hline Black & -0.035 & ( -0.069 to -0.001$)$ & 0.20 & (0.06 to 0.33$)$ \\
\hline Other & -0.06 & $(-0.09$ to -0.02$)$ & 0.07 & $(-0.05$ to 0.18$)$ \\
\hline \multicolumn{5}{|l|}{ Comorbidities } \\
\hline Hypertension & 0.13 & (0.10 to 0.15$)$ & 0.19 & (0.11 to 0.27$)$ \\
\hline Dyslipidemia & -0.03 & $(-0.05$ to -0.01$)$ & -0.10 & $(-0.18$ to -0.02$)$ \\
\hline Prior myocardial infarction & -0.06 & $(-0.09$ to -0.03$)$ & -0.13 & $(-0.19$ to -0.07$)$ \\
\hline Congestive heart failure & 0.12 & $(0.09$ to 0.16$)$ & -0.11 & $(-0.18$ to -0.04$)$ \\
\hline Family history of premature CAD & -0.07 & $(-0.10$ to -0.05$)$ & -0.02 & $(-0.08$ to 0.05$)$ \\
\hline Prior PCI & -0.02 & $(-0.04$ to 0.01$)$ & -0.87 & $(-0.93$ to -0.81$)$ \\
\hline End-stage renal disease & -0.01 & $(-0.08$ to 0.06$)$ & 0.51 & $(0.34$ to 0.69$)$ \\
\hline Cerebrovascular disease & 0.22 & $(0.18$ to 0.25$)$ & 0.20 & ( 0.12 to 0.27$)$ \\
\hline Peripheral vascular disease & 0.99 & (0.95 to 1.02$)$ & 0.92 & $(0.84$ to 0.99$)$ \\
\hline Chronic lung disease & 0.027 & $(0.002$ to 0.051$)$ & 0.04 & $(-0.03$ to 0.11$)$ \\
\hline Diabetes mellitus & -0.14 & $(-0.16$ to -0.12$)$ & -0.24 & $(-0.29$ to -0.18$)$ \\
\hline Commercial insurance & -0.08 & $(-0.10$ to -0.06$)$ & -0.17 & $(-0.24$ to -0.10$)$ \\
\hline \multicolumn{5}{|l|}{ Clinical presentation } \\
\hline No symptoms & Ref & Ref & Ref & Ref \\
\hline Atypical chest pain & -0.28 & $(-0.32$ to -0.27$)$ & -0.43 & $(-0.52$ to -0.33$)$ \\
\hline Stable angina & -0.22 & $(-0.25$ to -0.19$)$ & -0.19 & $(-0.28$ to -0.10$)$ \\
\hline Unstable angina & -0.27 & $(-0.30$ to -0.24$)$ & -0.37 & $(-0.45$ to -0.29$)$ \\
\hline Non-ST-segment elevation MI & -0.28 & $(-0.32$ to -0.24$)$ & -0.19 & $(-0.30$ to -0.08$)$ \\
\hline ST-segment elevation MI & 0.02 & $(-0.05$ to 0.09$)$ & 0.09 & $(-0.17$ to 0.35$)$ \\
\hline \multicolumn{5}{|l|}{ Indication } \\
\hline Rule out CAD & -0.33 & $(-0.37$ to -0.28$)$ & 0.10 & $(-0.03$ to 0.23$)$ \\
\hline Valvular heart disease & 1.35 & (1.32 to 1.39$)$ & 0.93 & (0.83 to 1.03$)$ \\
\hline Evaluation of cardiomyopathy & -0.18 & $(-0.20$ to -0.16$)$ & -0.27 & $(-0.33$ to -0.21$)$ \\
\hline $\begin{array}{l}\text { Pre-op evaluation for } \\
\text { noncardiac surgery }\end{array}$ & 0.04 & $(-0.01$ to 0.09$)$ & 0.12 & $(-0.04$ to 0.27$)$ \\
\hline Congenital heart disease & 3.22 & (3.06 to 3.39$)$ & 0.19 & $(-0.57$ to 0.95$)$ \\
\hline Cardiogenic shock within 24 hours & 0.21 & $(0.12$ to 0.31$)$ & -0.23 & $(-0.53$ to 0.06$)$ \\
\hline \multicolumn{5}{|l|}{ Arterial access site } \\
\hline Femoral & Ref & Ref & Ref & Ref \\
\hline Brachial & 4.69 & (4.56 to 4.82$)$ & 5.98 & (5.66 to 6.30$)$ \\
\hline Radial & 2.74 & (2.65 to 2.84$)$ & 3.59 & (3.18 to 4.00$)$ \\
\hline Intraaortic balloon pump inserted & 0.52 & $(0.44$ to 0.60$)$ & 0.15 & $(-0.17$ to 0.47$)$ \\
\hline $\begin{array}{l}\text { Concomitant right heart } \\
\text { catheterization }\end{array}$ & 2.75 & (2.72 to 2.78$)$ & 2.69 & (2.59 to 2.79$)$ \\
\hline \multicolumn{5}{|l|}{ Coronary artery stenosis present } \\
\hline Native coronary vessels & 0.80 & $(0.78$ to 0.83$)$ & 1.72 & (1.58 to 1.85$)$ \\
\hline Bypass grafts & $\mathrm{n} / \mathrm{a}$ & $\mathrm{n} / \mathrm{a}$ & 0.80 & (0.74 to 0.85$)$ \\
\hline $\begin{array}{l}\text { Operator volume } \\
\text { (/250 procedures per year) }\end{array}$ & -0.50 & $(-0.54$ to -0.41$)$ & -1.35 & $(-1.49$ to -1.22$)$ \\
\hline Operator subspecialty (interventional) & -0.18 & $(-0.27$ to -0.09$)$ & -1.23 & $(-1.46$ to -1.01$)$ \\
\hline Teaching hospital & 0.23 & $(0.17$ to 0.29$)$ & 0.32 & (0.17 to 0.48$)$ \\
\hline Hospital size $>250$ beds & -0.06 & $(-0.11$ to 0.00$)$ & -0.09 & $(-0.24$ to 0.07$)$ \\
\hline \multicolumn{5}{|l|}{ Census region } \\
\hline Northeast & Ref & Ref & Ref & Ref \\
\hline South & -0.06 & $(-0.16$ to 0.04$)$ & -0.98 & $(-1.23$ to -0.73$)$ \\
\hline Midwest & -0.12 & $(-0.23$ to -0.01$)$ & -0.81 & $(-1.07$ to -0.55$)$ \\
\hline West & -0.01 & $(-0.13$ to 0.11$)$ & -0.47 & $(-0.77$ to -0.18$)$ \\
\hline
\end{tabular}


TABLE IV. Continued

\begin{tabular}{|c|c|c|c|c|}
\hline \multirow{2}{*}{$\frac{\text { Variable }}{\text { Ownership }}$} & \multicolumn{2}{|c|}{ ICA } & \multicolumn{2}{|c|}{ ICA (prior CABG) } \\
\hline & & & & \\
\hline Private/community & Ref & Ref & Ref & Ref \\
\hline Government & 0.29 & (0.07 to 0.51$)$ & 0.05 & $(-0.48$ to 0.58$)$ \\
\hline University & 1.55 & (1.46 to 1.65 ) & 2.57 & (2.31 to 2.83 ) \\
\hline \multicolumn{5}{|l|}{ Year of procedure } \\
\hline 2005 & Ref & Ref & Ref & Ref \\
\hline 2006 & -0.02 & $(-0.05$ to 0.02$)$ & -0.04 & ( -0.14 to 0.06$)$ \\
\hline 2007 & -0.07 & ( -0.10 to -0.04$)$ & -0.23 & ( -0.32 to -0.13$)$ \\
\hline 2008 & -0.12 & $(-0.16$ to -0.09$)$ & -0.33 & $(-0.42$ to -0.23$)$ \\
\hline 2009 & -0.16 & $(-0.20$ to -0.13$)$ & -0.63 & $(-0.74$ to -0.52$)$ \\
\hline
\end{tabular}

CABG, coronary artery bypass graft; $\mathrm{CAD}$, coronary artery disease.

that it was tied directly to patient characteristics and procedural complexity, which are largely nonmodifiable factors. This finding alone highlights the need to consider "adjustment" of fluoroscopy time and other quality measures of radiation safety when benchmarking these procedures. Yet we also noted that operator and hospital-level factors, including operator volume, had a moderate impact on fluoroscopy time, contributing to nearly $20 \%$ of its variation even after accounting for differences in patient characteristics and procedure complexity.

These findings have important implications for quality improvement. First, outlining the distribution of fluoroscopy times for contemporary ICA and PCI provides a basis for defining national benchmarks for this measure. As cardiac catheterization labs increasingly adopt strategies for operators and their institutions to enhance the radiation safety of these procedures, these results provide a reference basis for gauging improvement. Second, we identified key patient and procedure factors associated with fluoroscopy time, which could be used to adjust such benchmarks to account for procedure complexity. This is important because of the strong correlation between procedure complexity and radiation exposure for both ICA and PCI. Finally, these findings highlight the potential for quality improvement by noting the important role that operator and hospital-level factors play in determining fluoroscopy times beyond patient characteristics and procedure complexity.

Our findings also have significant population health implications given the high prevalence of these procedures. For example, a modest reduction in fluoroscopy time for ICA from the 75th percentile to the 50th percentile translates into a $42 \%$ reduction in actual fluoroscopy time. Assuming a linear relationship between fluoroscopy time and KAP, this would lead to a proportionate decrease in effective dose, e.g., from $7 \mathrm{mSv}$ to $4.1 \mathrm{mSv}$ for the average ICA [20]. While such a dose reduction is small for an individual patient (roughly equivalent to annual US background radiation exposure from natural sources), it would translate to much more substantial, meaningful reductions in radiation exposure at the population level [21]. Importantly, simple technical measures such as increased use of collimation and reducing the dose-rate for fluoroscopy and cine could help achieve even greater reductions in radiation exposure from ICA and PCI. This highlights the importance and potential impact of efforts such as the Image Wisely campaign [22], which focuses on enhancing radiation safety of medical imaging, including fluoroscopic procedures, by educating health care professionals and patients. By partnering with such programs, the American Heart Association, American College of Cardiology and Society for Cardiac Angiography and Intervention could provide a much wider platform for these educational efforts among cardiologists and other health care providers. In order to narrow the current knowledge gap [23,24], it is also imperative that principles of radiation safety, including appropriate use of cardiac imaging and dose reduction techniques, be incorporated in cardiology fellowship training curricula in a meaningful manner. This knowledge should also be required for recertification of practicing operators.

Several key factors deserve to be highlighted given their potential for modification. For example, we found that operator volume was inversely associated with fluoroscopy time for ICA and PCI, a relationship that has been noted for other types of fluoroscopic procedures in prior studies [25]. This finding likely reflects the greater efficiency of more experienced operators and is consistent with the volume-outcomes relationship demonstrated for these procedures in previous studies [26,27]. Longer fluoroscopy times at university hospitals may be related to the involvement of trainees in procedures performed at these hospitals, which have been shown to increase fluoroscopy time for other fluoroscopic procedures [25,28]. From this standpoint, greater awareness and focus on radiation safety during 
TABLE V. Incremental PCI (with or without ICA) Fluoroscopy Time (in Minutes, with $95 \%$ Cl) Associated with Listed Variables After Multivariable Adjustment

\begin{tabular}{|c|c|c|c|c|c|c|}
\hline \multirow{2}{*}{$\frac{\text { Variable }}{\text { Female gender }}$} & \multicolumn{2}{|r|}{ PCI } & \multicolumn{2}{|c|}{ ICA and PCI } & \multicolumn{2}{|c|}{ ICA and PCI (prior CABG) } \\
\hline & -0.89 & $(-0.97$ to -0.81$)$ & -0.71 & $(-0.75$ to -0.67$)$ & -1.24 & $(-1.36$ to -1.13$)$ \\
\hline \multicolumn{7}{|l|}{ Age } \\
\hline Under 35 & -1.26 & $(-1.89$ to -0.62$)$ & -1.34 & $(-1.58$ to -1.10$)$ & -2.04 & $(-3.59$ to -0.49$)$ \\
\hline 35 to $<55$ & -1.92 & $(-2.05$ to -1.79$)$ & -2.10 & $(-2.16$ to -2.04$)$ & -2.16 & $(-2.34$ to -1.98$)$ \\
\hline 55 to $<75$ & -0.97 & $(-1.06$ to -0.87$)$ & -1.21 & $(-1.27$ to -1.16$)$ & -0.93 & $(-1.05$ to -0.82$)$ \\
\hline 75 or over & Ref & Ref & Ref & Ref & Ref & Ref \\
\hline Body mass index & 0.012 & (0.005 to 0.018$)$ & 0.024 & (0.021 to 0.028$)$ & 0.03 & (0.02 to 0.04$)$ \\
\hline \multicolumn{7}{|l|}{ Race } \\
\hline White & Ref & Ref & Ref & Ref & Ref & Ref \\
\hline Black & 0.08 & $(-0.08$ to 0.24$)$ & 0.17 & $(0.09$ to 0.25$)$ & 0.14 & $(-0.11$ to 0.38$)$ \\
\hline Other & -0.32 & $(-0.47$ to -0.16$)$ & -0.13 & $(-0.21$ to -0.06$)$ & 0.04 & $(-0.17$ to 0.24$)$ \\
\hline \multicolumn{7}{|l|}{ Comorbidities } \\
\hline Hypertension & 0.42 & $(0.31$ to 0.52$)$ & 0.41 & $(0.36$ to 0.46$)$ & 0.31 & $(0.17$ to 0.46$)$ \\
\hline Dyslipidemia & 0.21 & (0.11 to 0.30$)$ & 0.10 & $(0.05$ to 0.14$)$ & -0.02 & $(-0.18$ to 0.13$)$ \\
\hline Prior myocardial infarction & 0.21 & $(0.12$ to 0.30$)$ & 0.33 & $(0.28$ to 0.39$)$ & -0.01 & $(-0.11$ to 0.10$)$ \\
\hline Congestive heart failure & 0.05 & $(-0.07$ to 0.17$)$ & 0.15 & (0.07 to .22) & -0.13 & $(-0.26$ to 0.00$)$ \\
\hline Family history of premature CAD & -0.07 & $(-0.16$ to 0.03$)$ & -0.09 & $(-0.14$ to -0.05$)$ & -0.01 & $(-0.12$ to 0.11$)$ \\
\hline Prior PCI & -0.23 & $(-0.32$ to -0.14$)$ & -0.29 & $(-0.34$ to -0.24$)$ & -0.83 & $(-0.94$ to -0.73$)$ \\
\hline End-stage renal disease & 1.30 & (1.03 to 1.57$)$ & 1.19 & (1.04 to 1.35$)$ & 1.18 & $(0.86$ to 1.50$)$ \\
\hline Cerebrovascular disease & 0.20 & $(0.09$ to 0.31$)$ & 0.29 & $(0.22$ to 0.35$)$ & 0.05 & $(-0.08$ to -0.18$)$ \\
\hline Peripheral vascular disease & 0.89 & $(0.78$ to 1.00$)$ & 1.14 & (1.07 to 1.21$)$ & 0.75 & (0.62 to 0.87$)$ \\
\hline Chronic lung disease & 0.08 & $(-0.02$ to 0.18$)$ & 0.09 & $(0.03$ to 0.14$)$ & -0.15 & $(-0.28$ to -0.03$)$ \\
\hline Diabetes mellitus & -0.09 & $(-0.17$ to -0.01$)$ & -0.10 & $(-0.15$ to -0.06$)$ & -0.16 & $(-0.27$ to -0.06$)$ \\
\hline Commercial insurance & -0.12 & $(-0.21$ to -0.02$)$ & -0.13 & $(-0.09$ to 0.17$)$ & -0.27 & $(-0.39$ to -0.14$)$ \\
\hline \multicolumn{7}{|l|}{ Clinical presentation } \\
\hline No symptoms & Ref & Ref & Ref & Ref & Ref & Ref \\
\hline Atypical chest pain & -0.12 & $(-0.29$ to 0.06$)$ & -0.27 & $(-0.36$ to -0.18$)$ & -0.22 & $(-0.46$ to 0.02$)$ \\
\hline Stable angina & 0.11 & $(-0.01$ to 0.24$)$ & -0.03 & $(-0.11$ to 0.05$)$ & 0.15 & $(-0.04$ to 0.34$)$ \\
\hline Unstable angina & -0.05 & $(-0.17$ to 0.06$)$ & -0.48 & $(-0.55$ to -0.41$)$ & -0.14 & $(-0.31$ to 0.03$)$ \\
\hline Non-ST-segment elevation MI & -0.31 & $(-0.45$ to -0.16$)$ & -0.56 & $(-0.63$ to -0.48$)$ & -0.11 & $(-0.30$ to 0.09$)$ \\
\hline ST-segment elevation MI & -1.54 & $(-1.73$ to -1.35$)$ & -1.87 & $(-1.95$ to -1.79$)$ & -1.47 & $(-1.73$ to -1.20$)$ \\
\hline Cardiogenic shock within 24 hours & -0.24 & $(-0.59$ to 0.11$)$ & 0.22 & $(0.09$ to 0.35$)$ & -0.44 & $(-0.86$ to -0.03$)$ \\
\hline \multicolumn{7}{|l|}{ Arterial access site } \\
\hline Femoral & Ref & Ref & Ref & Ref & Ref & Ref \\
\hline Brachial & 4.58 & (4.03 to 5.12$)$ & 5.69 & $(5.36$ to 6.02$)$ & 7.24 & $(6.55$ to 7.93$)$ \\
\hline Radial & 1.27 & (0.90 to 1.64$)$ & 3.23 & (3.03 to 3.43$)$ & 3.27 & $(2.57$ to 3.96$)$ \\
\hline Intra-aortic balloon pump inserted & 3.74 & (3.43 to 4.04$)$ & 2.80 & (2.67 to 2.92$)$ & 3.06 & $(2.66$ to 3.46$)$ \\
\hline Concomitant right heart catheterization & na & na & 2.13 & (2.03 to 2.22$)$ & 2.15 & (1.91 to 2.38$)$ \\
\hline Number of lesions intervened upon & 3.95 & (3.90 to 4.00$)$ & 4.01 & (3.98 to 4.04$)$ & 3.88 & $(3.80$ to 3.96$)$ \\
\hline \multicolumn{7}{|l|}{ PCI lesion characteristics } \\
\hline Previously treated lesion & 0.33 & $(0.11$ to 0.55$)$ & 0.68 & $(0.57$ to 0.79$)$ & -0.23 & $(-0.44$ to -0.02$)$ \\
\hline Complex lesion (class C) & 3.81 & (3.73 to 3.83 ) & 2.91 & (2.87 to 2.95$)$ & 2.81 & $(2.71$ to 2.92$)$ \\
\hline Bifurcation lesion & 1.43 & (1.31 to 1.54$)$ & 1.53 & (1.47 to 1.59$)$ & 1.23 & $(1.06$ to 1.40$)$ \\
\hline \multicolumn{7}{|l|}{ PCI lesion location } \\
\hline Native coronary vessel & Ref & Ref & N/A & N/A & Ref & Ref \\
\hline Bypass graft-artery & -1.32 & $(-1.52$ to -1.11$)$ & & & -0.27 & $(-0.39$ to -0.15$)$ \\
\hline Bypass graft-vein & 0.53 & $(-0.02$ to 1.08$)$ & & & 1.48 & (1.14 to 1.82$)$ \\
\hline $\begin{array}{l}\text { Multiple locations (any combination } \\
\text { of above locations) }\end{array}$ & 0.80 & $(0.48$ to 1.13$)$ & & & 0.88 & $(0.65$ to 1.11$)$ \\
\hline \multicolumn{7}{|l|}{ Use of intracoronary devices } \\
\hline $\begin{array}{l}\text { Atherectomy, thrombectomy } \\
\text { catheter, or laser }\end{array}$ & 7.13 & (6.94 to 7.32$)$ & 2.75 & (2.66 to 2.83 ) & 5.06 & $(4.83$ to 5.29$)$ \\
\hline Embolic protection device & -0.78 & $(-1.08$ to -0.49$)$ & 2.14 & (1.61 to 2.67 ) & -0.07 & $(-0.28$ to 0.13$)$ \\
\hline \multicolumn{7}{|l|}{ Procedural complications } \\
\hline Significant dissection & 7.05 & (6.84 to 7.27$)$ & 6.33 & $(6.22$ to 6.44$)$ & 7.67 & (7.35 to 7.99$)$ \\
\hline Coronary perforation & 6.47 & (5.88 to 7.07$)$ & 4.43 & (4.12 to 4.73$)$ & 4.35 & (3.64 to 5.06$)$ \\
\hline No reflow phenomenon & 1.45 & (1.07 to 1.83$)$ & 1.72 & (1.56 to 1.89$)$ & 1.83 & $(1.45$ to 2.20$)$ \\
\hline $\begin{array}{l}\text { Operator volume } \\
\text { (/250 procedures per year) }\end{array}$ & -1.04 & $(-1.26$ to -0.81$)$ & -1.17 & $(-1.35$ to -0.99$)$ & -1.49 & $(-1.76$ to -1.22$)$ \\
\hline Teaching hospital & 0.22 & $(-0.02$ to 0.46$)$ & 0.42 & (0.30 to 0.54$)$ & 0.62 & (0.35 to 0.89$)$ \\
\hline
\end{tabular}


TABLE V. Continued

\begin{tabular}{|c|c|c|c|c|c|c|}
\hline \multirow{2}{*}{$\frac{\text { Variable }}{\text { Hospital size }>250 \text { beds }}$} & \multicolumn{2}{|r|}{ PCI } & \multicolumn{2}{|c|}{ ICA and PCI } & \multicolumn{2}{|c|}{ ICA and PCI (prior CABG) } \\
\hline & -0.18 & $(-0.45$ to 0.09$)$ & -0.11 & $(-0.23$ to 0.01$)$ & 0.23 & $(-0.06$ to 0.52$)$ \\
\hline \multicolumn{7}{|l|}{ Census region } \\
\hline Northeast & Ref & Ref & Ref & Ref & Ref & Ref \\
\hline South & -1.21 & $(-1.63$ to -0.80$)$ & -0.75 & $(-1.01$ to -0.50$)$ & -1.52 & $(-1.98$ to -1.06$)$ \\
\hline Midwest & -1.06 & ( -1.50 to -0.61$)$ & -0.86 & $(-1.14$ to -0.58$)$ & -1.08 & $(-1.57$ to -0.59$)$ \\
\hline West & 0.50 & $(0.01$ to 0.99$)$ & 0.01 & $(-0.29$ to 0.30$)$ & 0.01 & $(-0.52$ to 0.54$)$ \\
\hline \multicolumn{7}{|l|}{ Ownership } \\
\hline Private/community & Ref & Ref & Ref & Ref & Ref & Ref \\
\hline Government & -0.97 & $(-1.85$ to -0.09$)$ & -0.46 & $(-1.07$ to 0.15$)$ & -0.51 & $(-1.63$ to 0.61$)$ \\
\hline University & 3.64 & (3.26 to 4.01$)$ & 2.95 & (2.75 to 3.14$)$ & 4.88 & (4.47 to 5.29$)$ \\
\hline \multicolumn{7}{|l|}{ Year of procedure } \\
\hline 2005 & Ref & Ref & Ref & Ref & Ref & Ref \\
\hline 2006 & -0.23 & $(-0.36$ to -0.10$)$ & -0.33 & $(-0.40$ to -0.26$)$ & -0.14 & $(-0.32$ to 0.03$)$ \\
\hline 2007 & -0.59 & ( -0.72 to -0.46$)$ & -0.66 & $(-0.73$ to -0.59$)$ & -0.64 & ( -0.82 to -0.46$)$ \\
\hline 2008 & -0.77 & ( -0.90 to -0.63$)$ & -0.93 & $(-1.00$ to -0.86$)$ & -0.94 & ( -1.11 to -0.76$)$ \\
\hline 2009 & -1.06 & $(-1.22$ to -0.91$)$ & -1.25 & $(-1.33$ to -1.17$)$ & -1.46 & $(-1.66$ to -1.26$)$ \\
\hline
\end{tabular}

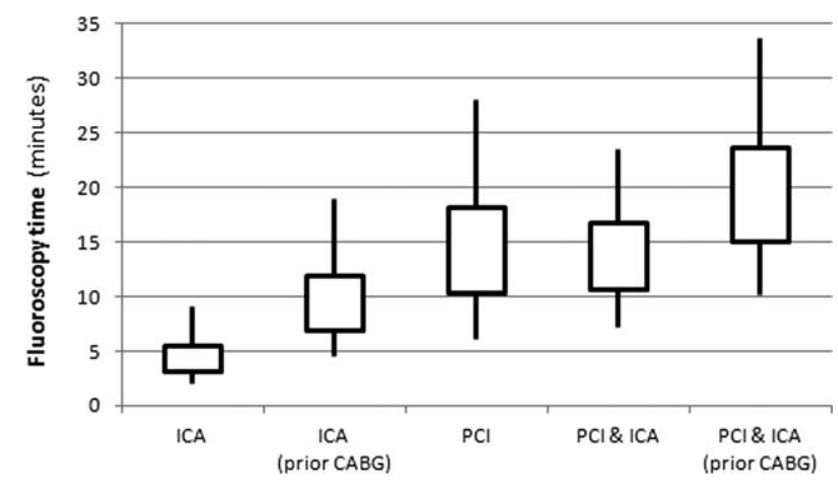

Fig. 3. Distribution of average physician-level fluoroscopy times for invasive coronary angiography (ICA) and percutaneous coronary intervention ( $\mathrm{PCl}$ ). The boxplots denote the interquartile ranges and the lower and upper whiskers display the 5th and 95th percentiles, respectively. CABG indicates coronary artery bypass graft.

training may improve the use of these procedures [29]. Finally, modest regional variation in PCI fluoroscopy times noted in our study may be related to differences in rates of adoption of newer fluoroscopy cameras (with options such as last image hold or cine loop that allow reduction in fluoroscopy times), operator volume and experience, awareness of radiation safety principles, and local efforts to reduce fluoroscopy time. It is important to develop further understanding of operator and hospital determinants of fluoroscopy time, as they will provide insights into specific approaches that may improve radiation safety.

We identified other factors associated with increased fluoroscopy time, but the extent to which these factors are modifiable is less clear. Nonfemoral arterial access, particularly brachial arterial access, was associated with significantly longer fluoroscopy times for both ICA and PCI. As brachial arterial access is often obtained after Catheterization and Cardiovascular Interventions DOI 10.1002/ccd.

Published on behalf of The Society for Cardiovascular Angiography and Interventions (SCAI). failed attempts to gain radial and/or femoral arterial access, the added fluoroscopy time associated with this approach may be a reflection of difficult arterial access in patients with peripheral vascular disease. The presence of coronary stenosis was associated with longer fluoroscopy times, which may be related to the additional images and views needed to accurately characterize lesions. Factors contributing to longer fluoroscopy times in the elderly probably include a combination of the above factors, i.e., more difficult access because of increased peripheral vascular disease as well as more coronary disease requiring additional images to define coronary anatomy. In patients with congenital heart disease, navigation of and defining the complex anatomy likely adds to the fluoroscopy time. The shorter fluoroscopy times in patients presenting with STEMI may be related to the more time-sensitive nature of these interventions where the operator's primary goal is reestablishing coronary flow as quickly as possible. Finally, possible causes of the modest decrease in average fluoroscopy times over time during the study period include improved image quality with newer cameras, the increased availability of options such as last image hold and loop replay, and increasing awareness of radiation safety principles among operators.

Finally, several patient and procedure-related factors that we identified as being associated with increased fluoroscopy time are less predictable and should probably be used to place excessive radiation exposures, when they occur, into appropriate clinical context. For example, operators typically only utilize atherectomy, thrombectomy, or extraction catheters or laser when lesion complexity necessitates their use. Similarly, there are much more pressing reasons to avoid complications such as coronary dissection or perforation than risks related to radiation exposure. However, understanding 


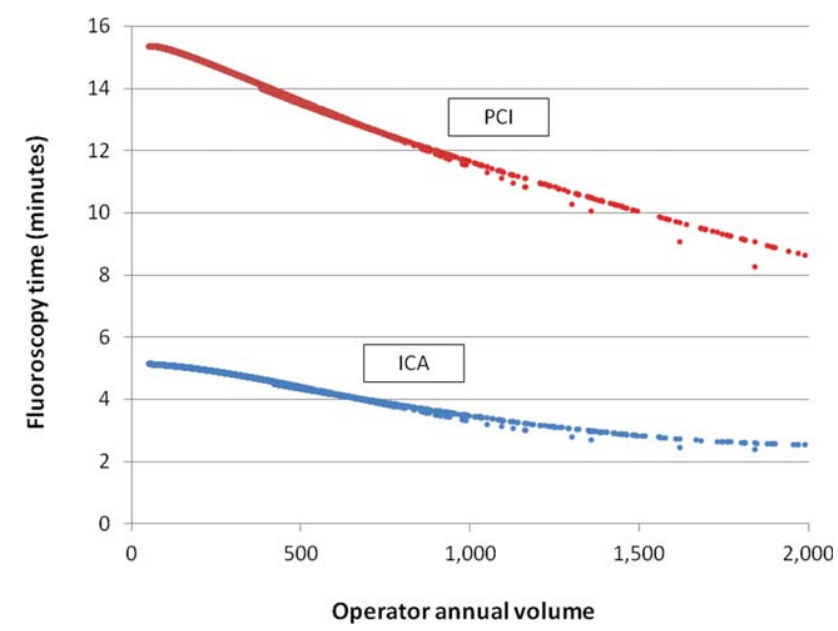

Fig. 4. Operator volume-fluoroscopy time relationship for invasive coronary angiography (ICA) and percutaneous coronary intervention $(\mathrm{PCl})$.

the relationship between these factors and increased fluoroscopy time may still be useful in these settings. Fluoroscopy time cannot be used as an indicator of peak skin dose because it does not account for key determinants of peak dose such as dose-rate, projection angles, cine use, and patient size. However, in cases with prolonged fluoroscopy times, operators should pay even closer attention to monitoring total air kerma at the reference point (also known as cumulative air kerma), which indicates peak skin dose. Attention to the principles of radiation safety with fluoroscopy (Table VI) is particularly important in such cases. In our study, fluoroscopy times exceeded 30 minutes in $8.1 \%$ of PCIs and 60 minutes in $0.8 \%$ of PCIs. In cases in which the total air kerma at the reference point exceeds $5 \mathrm{~Gy}$, early follow-up and more extensive patient education to monitor for skin injury is appropriate [9]. Both total air kerma at the reference point and air kerma-area product are reported by all fluoroscopy machines manufactured since 2006 as mandated by the Food and Drug Administration [30]. Registries such as the CathPCI Registry should incorporate these measures in order to provide more accurate and meaningful feedback regarding radiation safety to participating hospitals.

Our study should be interpreted in the context of the following limitations. First, because of the limitations of our data source, we used fluoroscopy time rather than air kerma-area product which is admittedly a more appropriate and accurate estimate of radiation exposure [9]. However, prior studies have shown that for ICA and PCI, in contrast to noncardiac fluoroscopic procedures, there is a good correlation between fluoroscopy time and air kerma-area product (published estimates of correlation coefficient $[R]=73 \%$ to $78 \%$ ), and fluoroscopy time is a modifiable and easily
TABLE VI. Fluoroscopic Dose-Rate Management Techniques

- Keep the patient as close as reasonably possible to the image receptor and as far as possible from the x-ray tube.

- Use collimation to reduce the irradiated area.

- Use the lowest acceptable magnification.

- Use the lowest clinically acceptable dose-rate at all times.

- Use fluoroscopy only for real-time imaging guidance.

- Use image acquisition (Cine or DSA) only when higher-quality image review is essential.

- Use last-image-hold or loop replay in place of live imaging whenever practicable. In some cases, retrospectively stored fluoroscopy may replace image acquisition.

- Minimize the number of cine series.

- Never use cine as a substitute for fluoroscopy.

- Use wedge filters when they are appropriate.

- Try to avoid steeply angulated projections (especially LAO cranial).

- Try to vary the C-arm angulation slightly, to avoid concentrating the radiation dose at a single site on the patient's skin.

- Remember that for large patients, and also for steeply angulated projections, the dose to the patient increases substantially.

- Pay attention to the patient radiation dose display in the procedure room.

- If the patient has had previous similar procedures, try to obtain information about the previous radiation doses to optimize subsequent procedures.

Adapted from NCRP-168 and ICRP Draft Report for Consultation on Patient and Staff Radiological Protection in Cardiology.

understandable factor that is responsible for the majority of its variation across these procedures [6,8,9]. Second, we defined operator volume based on procedures recorded in the CathPCI Registry and did not capture procedures performed in other (non-CathPCI Registryparticipating) hospitals. As this approach is likely to lead to underestimations of operator volume, it would minimize the degree of associations between operator volume and fluoroscopy time that we identified. Finally, we excluded procedures for which key data were missing, but these constituted a very small proportion $(<2 \%)$ of the overall procedures and their exclusion was unlikely to create a significant bias in the study results.

\section{CONCLUSIONS}

There is wide variation in fluoroscopy times for ICA and PCI procedures. Operator and hospital factors contribute significantly to this variation and provide potential targets for improving the radiation safety of these procedures.

\section{ACKNOWLEDGMENT}

The views expressed in this manuscript represent those of the author(s), and do not necessarily represent the official views of the NCDR or its associated professional societies identified at www.ncdr.com."

Catheterization and Cardiovascular Interventions DOI 10.1002/ccd. Published on behalf of The Society for Cardiovascular Angiography and Interventions (SCAI) 


\section{REFERENCES}

1. Go AS, Mozaffarian D, Roger VL, Benjamin EJ, Berry JD, Borden WB, Bravata DM, Dai S, Ford ES, Fox CS, Franco S, Fullerton HJ, Gillespie C, Hailpern SM, Heit JA, Howard VJ, Huffman MD, Kissela BM, Kittner SJ, Lackland DT, Lichtman JH, Lisabeth LD, Magid D, Marcus GM, Marelli A, Matchar DB, McGuire DK, Mohler ER, Moy CS, Mussolino ME, Nichol G, Paynter NP, Schreiner PJ, Sorlie PD, Stein J, Turan TN, Virani SS, Wong ND, Woo D, Turner MB. Heart disease and stroke statistics-2013 update: A report from the American Heart Association. Circulation 2013;127:e6-e245.

2. National Council on Radiation Protection and Measurements. NCRP Report No. 160, Ionizing Radiation Exposure of the Population of the United States. Bethesda, MD: National Council on Radiation Protection and Measurements; March 2009.

3. Fazel R, Krumholz HM, Wang Y, Ross JS, Chen J, Ting HH, Shah ND, Nasir K, Einstein AJ, Nallamothu BK. Exposure to low-dose ionizing radiation from medical imaging procedures. $\mathrm{N}$ Engl J Med 2009;361:849-857.

4. Chen J, Einstein AJ, Fazel R, Krumholz HM, Wang Y, Ross JS, Ting HH, Shah ND, Nasir K, Nallamothu BK. Cumulative exposure to ionizing radiation from diagnostic and therapeutic cardiac imaging procedures: A population-based analysis. J Am Coll Cardiol 2010;56:702-711.

5. Sources and effects of ionizing radiation: United Nations Scientific Committee on the Effects of Atomic Radiation (UNSCEAR) 2008 report to the General Assembly, with scientific annexes. Vol 1, Sources. New York, NY: United Nations, 2010.

6. den Boer A, de Feijter PJ, Serruys PW, Roelandt JR. Real-time quantification and display of skin radiation during coronary angiography and intervention. Circulation 2001;104:1779-1784.

7. Pantos I, Patatoukas G, Katritsis DG, Efstathopoulos E. Patient radiation doses in interventional cardiology procedures. Curr Cardiol Rev 2009;5:1-11.

8. Bor D, Olgar T, Toklu T, Caglan A, Onal E, Padovani R. Patient doses and dosimetric evaluations in interventional cardiology. PhysMedica 2009;25:31-42.

9. National Council on Radiation Protection and Measurements. NCRP Report No. 168, Radiation Dose Management for Fluoroscopically-Guided Interventional Medical Procedures. Bethesda, MD: National Council on Radiation Protection and Measurements; July 2010.

10. International Commission on Radiation Units and Measurements. ICRU Report 74. Patient dosimetry for $\mathrm{X}$ rays used in medical imaging. Bethesda, MD, International Commission on Radiation Units and Measurements; September 2009.

11. The 2007 Recommendations of the International Commission on Radiological Protection. ICRP publication 103. Ann ICRP 2007; 37:1-332.

12. Prasad KN, Cole WC, Haase GM. Radiation protection in humans: Extending the concept of as low as reasonably achievable (ALARA) from dose to biological damage. Br J Radiol 2004;77:97-99.

13. Balter S. Radiation safety in the cardiac catheterization laboratory: Operational radiation safety. Catheter Cardio Inte 1999;47: 347-353.

14. Bashore T. Fundamentals of X-ray imaging and radiation safety. Catheter Cardio Inte 2001;54:126-135.

15. Weintraub WS, McKay CR, Riner RN, Ellis SG, Frommer PL, Carmichael DB, Hammermeister KE, Effros MN, Bost JE, Bodycombe DP. The American College of Cardiology National Database: Progress and challenges. American College of Cardi- ology Database Committee. J Am Coll Cardiol 1997;29:459465.

16. Brindis RG, Fitzgerald S, Anderson HV, Shaw RE, Weintraub WS, Williams JF. The American College of CardiologyNational Cardiovascular Data Registry (ACC-NCDR): Building a national clinical data repository. J Am Coll Cardiol 2001;37: 2240-2245.

17. http://www.ncdr.com/WebNCDR/NCDRDocuments/datadictdefsonlyv30. pdf. Last accessed 12/12/11.

18. http://www.ncdr.com/WebNCDR/NCDRDocuments/CathPCI_v4_ CodersDictionary_4.4.pdf, last accessed 11/18/2011.

19. Austin PC, Tu JV, Alter DA. Comparing hierarchical modeling with traditional logistic regression analysis among patients hospitalized with acute myocardial infarction: Should we be analyzing cardiovascular outcomes data differently? Am Heart J 2003; 145:27-35.

20. Mettler FA Jr, Huda W, Yoshizumi TT, Mahesh M. Effective doses in radiology and diagnostic nuclear medicine: A catalog. Radiology 2008;248:254-263.

21. Einstein AJ. Effects of radiation exposure from cardiac imaging: How good are the data? J Am Coll Cardiol 2012;59:553-565.

22. http://www.imagewisely.org/?CSRT=10794036780689157081, last accessed 12/5/11.

23. Lee CI, Haims AH, Monico EP, Brink JA, Forman HP. Diagnostic CT scans: Assessment of patient, physician, and radiologist awareness of radiation dose and possible risks. Radiology 2004;231:393-398.

24. Quinn AD, Taylor CG, Sabharwal T, Sikdar T. Radiation protection awareness in non-radiologists. Br J Radiol 1997;70: $102-106$.

25. Jorgensen JE, Rubenstein JH, Goodsitt MM, Elta GH. Radiation doses to ERCP patients are significantly lower with experienced endoscopists. Gastrointest Endosc 2010;72:58-65.

26. Hannan EL, Racz M, Ryan TJ, McCallister BD, Johnson LW, Arani DT, Guerci AD, Sosa J, Topol EJ. Coronary angioplasty volume-outcome relationships for hospitals and cardiologists. JAMA 1997;277:892-898.

27. McGrath PD, Wennberg DE, Dickens JD Jr, Siewers AE, Lucas FL, Malenka DJ, Kellett MA Jr, Ryan TJ Jr. Relation between operator and hospital volume and outcomes following percutaneous coronary interventions in the era of the coronary stent. JAMA 2000;284:3139-3144.

28. Kim E, McLoughlin M, Lam EC, Amar J, Byrne M, Telford J, Enns R. Prospective analysis of fluoroscopy duration during ERCP: Critical determinants. Gastrointest Endosc 2010;72:5057.

29. Hirshfeld JW Jr, Balter S, Brinker JA, Kern MJ, Klein LW, Lindsay BD, Tommaso CL, Tracy CM, Wagner LK, Creager MA, Elnicki M, Lorell BH, Rodgers GP, Weitz HH, American College of Cardiology F, American Heart A, Hrs, Scai, American College of Physicians Task Force on Clinical C, Training. ACCF/AHA/HRS/SCAI clinical competence statement on physician knowledge to optimize patient safety and image quality in fluoroscopically guided invasive cardiovascular procedures: A report of the American College of Cardiology Foundation/American Heart Association/American College of Physicians Task Force on Clinical Competence and Training. Circulation 2005; 111:511-532.

30. U.S. Food and Drug Administration. "Performance standards for ionizing radiation emitting products. Fluoroscopic equipment, Air kerma rates," 21 CFR Part 1020.32(d) (revised April 1, 2011), http://www.accessdata.fda.gov/scripts/cdrh/cfdocs/cfcfr/ CFRSearch.cfm (accessed November 25, 2011) (U.S. Government Printing Office, Washington).

Catheterization and Cardiovascular Interventions DOI 10.1002/ccd.

Published on behalf of The Society for Cardiovascular Angiography and Interventions (SCAI). 


\section{APPENDIX}

Fluoroscopy times (in minutes) of procedures in the CathPCI

Registry during the study period in which the operator ID was known (included in analysis) and unknown (excluded from the analysis)

\begin{tabular}{lcc}
\hline \multicolumn{1}{c}{ Distribution } & $\begin{array}{c}\text { Operator known } \\
(\mathrm{n}=3,321,988)\end{array}$ & $\begin{array}{c}\text { Operator unknown } \\
(\mathrm{n}=1,142,130)\end{array}$ \\
\hline Mean & 9.26 & 9.21 \\
Std Deviation & 10.57 & 10.67 \\
$100 \%$ (maximum) & 300.0 & 300.0 \\
$99 \%$ & 48.1 & 48.4 \\
$95 \%$ & 28.0 & 28.1 \\
$90 \%$ & 20.7 & 20.7 \\
$75 \%$ (3rd quartile) & 12.0 & 12.0 \\
$50 \%$ (median) & 6.0 & 5.9 \\
$25 \%$ (1 quartile) & 2.7 & 2.6 \\
$10 \%$ & 1.5 & 1.5 \\
$5 \%$ & 1.2 & 1.2 \\
$1 \%$ & 0.8 & 0.8 \\
$0 \%$ (minimum) & 0.0 & 0.0 \\
\hline
\end{tabular}

